\title{
The Ethics of Making Patients Responsible
}

\author{
SVEN OVE HANSSON
}

\begin{abstract}
In their daily clinical work, healthcare professionals generally apply what seems to be a double standard for the responsibility of patients. On the one hand, patients are encouraged to take responsibility for lifestyle changes that can improve their chances of good health. On the other hand, when patients fail to follow such recommendations, they are not held responsible for the failure. This seeming inconsistency is explained in terms of the distinction between task responsibility and blame responsibility. The double standard for responsibility is shown to be epistemologically rational, ethically commendable, and therapeutically advantageous. However, this non-blaming approach to patient responsibility is threatened by proposals to assign lower priority in healthcare to patients who are themselves responsible for their disease. Such responsibility-based priority setting requires that physicians assign blame responsibility to their patients, a practice that would run into conflict with the ethical foundations of the patient-physician relationship. Therefore, such proposals should be rejected.
\end{abstract}

Keywords: blame; clinical encounter; ethics; lifestyle; obesity; patient-physician relationship; priority setting; responsibility; self-blame; smoking; victim blaming

\section{Introduction}

First Visit

Physician. I will give you a recipe for a medicine, but unfortunately it can only alleviate the acute pain. What you really need is to quit smoking and lose weight.

PATIENT. Would that make me healthy?

Physician. The tissue damage will not disappear, but we can prevent the disease from progressing. You will feel better and be less tired.

Patient. So what do you want me to do?

PHYSICIAN. I will give you a referral to a nutritionist who can help you to eat better. Then it is up to you to follow her advice and to do some exercise. Do you take any exercise now, such as walks?

Patient. No, actually not much.

Physician. Then I propose that you start by taking half an hour's walk every day. It is fine if you walk as fast as you can, but the important thing is that you actually do it every day. I will also give you a referral to the Smoking Cessation Clinic for support sessions and perhaps a nicotine replacement.

Patient. That gives me a lot to do. But I will try hard.

Physician. I am convinced that you will succeed. If you make a good effort and follow our advice you have every chance to succeed. 
Physician. You weigh 5 kilos more than last time we met. Did you go to the nutritionist?

PATIENT. Yes, but it was more difficult than I had thought to change my diet.

Physician. I understand. What about smoking?

Patient. It's like before. About 30 a day.

Physician. Have you been to the Smoking Cessation Clinic?

Patient. Yes, and they were very friendly and tried to help me. But the cravings were too strong. I had 8 smoke-free days, but then I could not resist the urge any more.

Physician. And the exercise? The walks that I recommended?

Patient. The first week I want to the park and back every morning. That took almost half an hour. But then I ran out of steam somehow. I am very sorry, all this is really bad of me.

Physician. I could not agree more. This is certainly bad of you. You have failed to follow each of my three recommendations. And as I said last time, if you had made a real effort you would have been almost certain to succeed. All this is your own fault and it is your own responsibility that the disease has worsened since last time you were here.

Something went wrong here! This is not what the physician was expected to say. The following would have been more in line with expectations:

Physician. I can understand that you are disappointed but now we have to look ahead. Perhaps it was unrealistic of me to start with three such difficult changes at the same time. It is probably better to take them one at a time. I believe that smoking is the most important of them, but I want you to decide for yourself what to start with. What do you say? Would it be a good idea to select one of them to start with?

Why does the first version of the physician's response come across as unprofessional? In that response, she was fully consistent. In the first consultation she told the patient that it was possible for him to quit smoking and begin to exercise and eat better. She placed the responsibility on the patient, which was adequate, because only the patient himself could change his habits. At the second visit she found that he had not at all fulfilled his responsibilities. It is a basic principle in medical ethics that patients have a right to be told the truth; therefore, how could it have been wrong to tell him this?

\section{Different Types of Responsibility}

In order to answer that question it is important to distinguish between different types of responsibility.

Gerald Dworkin listed three major types of responsibility; namely role responsibility, causal responsibility, and liability responsibility. ${ }^{1}$ His use of the term "role 
responsibility" is based on the assumption that each of us has a "role" as a human being, and that this role includes responsibilities toward oneself. Goodin proposed that the term "role responsibility" be replaced by the more transparent "task responsibility." 2 For present purposes it is useful to divide the notion of responsibility into the three variants (or parts): causal responsibility, blame responsibility (accountability), and task responsibility. Having causal responsibility for one's disease means to have causally contributed to it, having blame responsibility means to be blameworthy for it, and having a task responsibility means to be obliged to take measures against it.

Causal responsibility will not be further discussed in this article. The crucial distinction that is needed is that between task responsibility and blame responsibility. To explain it further, I will use a different type of example. Suppose that I am responsible for the supply of oxygen to the operating rooms. This involves a task responsibility; namely, making sure that there is at all times a reliable supply of oxygen. It also involves a blame responsibility, which means that I can be blamed and held accountable if the oxygen supply fails. In this and many other cases, the task responsibility and the blame responsibility follow each other; however, there are also cases when they do not.

The major claim that I want to make is that in their daily clinical work, healthcare professionals apply a well-developed practice for patient responsibility, a practice that is seldom articulated or explicitly discussed. ${ }^{3}$ That practice consists in distinguishing between the task responsibility and the blame responsibility of patients in the way indicated in the second version of the preceding dialogue: Patients are encouraged to take (task) responsibility for doing what they can to promote their own health, but if they fail, they are not burdened with (blame) responsibility for their failure. This approach to responsibility can be described as a type of "tacit knowledge" shared by healthcare professionals. In the remainder of this article I will discuss how it can be justified, and propose that it needs to be defended against current trends in healthcare priority setting.

\section{Why Limit Ascriptions of Blame Responsibility?}

There are at least four valid justifications for assigning much more task responsibility than blame responsibility to patients: one epistemic, one deontological, and two consequentialist justifications.

The epistemic justification is based on the two simple observations that (1) many of the changes in lifestyles that are desirable for health promotion are in fact quite difficult to carry through, and (2) physicians cannot know how difficult they are for the individual patient. We have all on occasions failed to do what we intended, and both hunger and nicotine urge appear to be almost impossible to resist for some persons, however hard they try. If it were easy to quit smoking or lose weight there would presumably not have been many smokers or obese persons around.

This can be illustrated with probabilistic reasoning. For a simple (and admittedly simplistic) example, suppose that 90 percent of all patients with a certain condition have the ability to carry through a desirable behavioral change (such as to quit smoking). Furthermore, suppose that two thirds of the patients who have this ability will make the efforts required to succeed. A physician who meets a patient with this condition for the first time can count on a 90 percent probability that the patient has the ability to succeed. Now suppose that the patient comes back a few 
months later and turns out to have failed; for example, the patient is still smoking. The physician still does not know if it would have been possible for that patient to succeed if he or she had tried harder. A simple calculation shows that there is a 75 percent probability that the patient could have done so. ${ }^{4}$ For purely epistemic reasons, a physician may choose to say "you can" to the patient if the probability is 90 percent that he or she actually has the ability in question, but not if the probability is 75 percent. Obviously, what is important in this example is not the numbers, but the simple insight that they illustrate: The proportion of patients who are at all capable of carrying through a difficult behavioral change is smaller among those who try and fail than among all of those who try. This can be reason enough to say "You can do it" to patients who are recommended to implement difficult changes in their lives, but to refrain from saying "You could have done it" to those who come back and have failed.

The deontological justification is directly based on the epistemic one. A duty often referred to is that of speaking the truth. Its violation appears to be particularly serious when it takes the form of accusing a person of something that the person is not guilty of having done. Physicians will not, in general, know whether particular patients have failed to do their very best, for example, to reduce their weight. This uncertainty is reason enough not to accuse such patients of having done so.

The first consequentialist justification refers to the consequences for patients' abilities to change their unhealthy life patterns. There are reasons to believe that the chances that patients will succeed in doing so are higher if they make this their goal and if they are also encouraged to believe that they can actually succeed in achieving it. ${ }^{5}$ Therefore, positive effects can be expected if a physician assigns the (task) responsibility to a patient and puts emphasis on the possibilities of actually succeeding. The situation is different for patients who come back reporting that they were unsuccessful. There are no reasons to believe that those patients will be helped by being blamed for the failure. In the case of obesity there is evidence to the contrary. Patients exposed to stigmatization and blaming are less successful than other patients in losing weight. ${ }^{6}$ It follows that a practice emphasizing the patient's task responsibility but deemphasizing the patient's blame responsibility can be expected to be an efficient means to achieve health-conducive habits.

The second consequentialist justification refers to the direct effects of blame responsibility on the patient's psychological condition. There is evidence that patients suffer from being told that their disease is their own fault. Obesity "has come to be not only an undesirable physical attribute, it is also considered a moral failure. Obese people, especially those who are morbidly obese, are commonly thought to be irresponsible, immature, hedonic, undisciplined, sickly, defiant, and morally disgusting." 7 A study of obese children between 9 and 11 years of age showed that those believing themselves to be responsible for their condition had lower selfesteem than those who attributed it to factors external to themselves. ${ }^{8}$ A study of lung cancer patients showed that "whether they smoked or not, they felt particularly stigmatised because the disease is so strongly associated with smoking. Interaction with family, friends, and doctors was often affected as a result, and many patients, particularly those who had stopped smoking years ago or had never smoked, felt unjustly blamed for their illness." 9 Other studies confirm that patients who blame themselves for the disease and attribute it to their own 
behavior run an increased risk of negative mental health outcomes such as depression. ${ }^{10}$ In conclusion, the suffering of sick people can be increased by telling them that their suffering is their own fault. Obviously, this is a consequentialist reason not to convey such messages. ${ }^{11}$

All this gives healthcare workers good reasons to choose ways of communicating with patients that reduce the risk of self-blame as far as possible. For example, physicians recommending patients with lung cancer to quit smoking may choose to "emphasise the potential role of smoking on disease recurrence or metastasis, rather than on smoking as the initial cause of the cancer."12

\section{The Debate on Priority Setting}

Since the 1990s, patients' responsibility for their own disease has been increasingly highlighted in discussions on priority setting in healthcare. It has been argued that patients who have caused their own disease should be assigned lower priority than those affected through no fault of their own. ${ }^{13}$ This discussion has referred mainly to two types of priority setting. First, it has been maintained that patients who are themselves responsible for their disease should not be covered by the insurances needed for access to healthcare in countries such as the United States that lack a universal healthcare system. Examples commonly referred to are patients with smoking-related diseases ${ }^{14}$ and alcoholics in need of a liver transplant. ${ }^{15}$ Second, it has been proposed that patients who have caused their own disease should be assigned a position further down in healthcare queues such as queues for transplantation. ${ }^{16}$

The introduction of responsibility-based priority setting would have a considerable impact on the patient-physician relationship. ${ }^{17}$ If patients have to be assigned to different treatments or different queues depending on their (blame) responsibility for their own disease, then the task of determining how responsible each of them is for their own medical condition will unavoidably fall to their physicians. The physician will be given the additional task of tracking down faults in the patients' ways of life and curtailing access to treatment in accordance with these faults. Such activities on part of the physician are obviously incompatible with the current practice to avoid blaming patients for their disease, a practice that was shown previously to be a well-established and beneficial component of professional healthcare.

Priority setting by blame would also invalidate the old advice "always to tell your doctor the truth." 18 Patients who risk decreased access to healthcare if they have smoked or eaten an unhealthy diet would gain from not telling their physicians the truth about these previous habits. Incomplete or false information from the patient increases the risk of incorrect diagnosis and inadequate treatment. The basic ethical commitment of the healthcare professions is to do what improves, not what worsens, the health of patients. Victim-blaming priority setting would run contrary to this commitment and should therefore be rejected.

\section{Notes}

1. Dworkin G. Voluntary health risks and public policy: Taking risks, assessing responsibility. Hastings Centre Report 1981;11:26-31.

2. Goodin RE. Apportioning responsibilities. Law and Philosophy 1987;6:167-85.

3. Kelley made a similar remark in terms of the related distinction between forward- and backwardlooking responsibility. See: Kelley M. Limits on patient responsibility. Journal of Medicine and Philosophy 2005;30:189-206. 


\section{Sven Ove Hansson}

4. Among 100 patients, there will be 60 who can stop smoking and also do so, 30 who can quit but do not do so, and 10 who are unable to quit. Therefore, 30 of the 40 who did not quit (75 percent) would have been able to do so.

5. Locke EA, Latham GP. A Theory of Goal Setting and Task Performance. Englewood Cliffs, NJ: Prentice Hall; 1990; Nelissen R, de Vet E, Zeelenberg M. Anticipated emotions and effort allocation in weight goal striving. British Journal of Health Psychology 2011;16(1):201-12.

6. Eisenberg ME, Neumark-Sztainer D, Story M. Associations of weight-based teasing and emotional well-being among adolescents. Archives of Pediatrics and Adolescent Medicine 2003;157(8):733-8; Puhl RM, Moss-Racusin CA, Schwartz MB. Internalization of weight bias: Implications for binge eating and emotional well-being. Obesity 2007;15(1):19-23; Neumark-Sztainer D, Falkner N, Story M, Perry C, Hannan PJ, Mulert S. Weight-teasing among adolescents: Correlations with weight status and disordered eating behaviors. International Journal of Obesity 2002;26:123-31; Adler NE, Stewart J. Reducing obesity: motivating action while not blaming the victim. Milbank Quarterly 2009;87:49-70.

7. Banja J. Obesity, responsibility and empathy. Case Manager 2004;15:43-6. Quotation at 43.

8. Pierce JW, Wardle K. Cause and effect beliefs and self-esteem of overweight children. Journal of Child Psychology and Psychiatry 1997;38(6):645-50.

9. Chapple A, Ziebland S, McPherson A. Stigma, shame, and blame experienced by patients with lung cancer: Qualitative study BMJ 2004;328(7454):1470; compare Hamann HA, Ostroff JS, Marks EG, Gerber DE, Schiller JH, Craddock Lee SJ. Stigma among patients with lung cancer: A patientreported measurement model. Psycho-Oncology 2014;23(1):81-92.

10. Phelan SM, Griffin JM, Jackson GL, Zafar SY, Hellerstedt W, Stahre M, et al. Stigma, perceived blame, self-blame, and depressive symptoms in men with colorectal cancer. Psycho-Oncology 2013;22(1):65-73; Else-Quest NM, LoConte NK, Schiller JH, Hyde JS. Perceived stigma, self-blame, and adjustment among lung, breast and prostate cancer patients. Psychology and Health 2009;24(8):949-64.

11. Guttman N, Ressler WH. On being responsible: Ethical issues in appeals to personal responsibility in health campaigns. Journal of Health Communication: International Perspectives 2001;6:117-36.

12. See note 10, Else-Quest et al 2009, at 960.

13. Sharkey K, Gillam L. Should patients with self-inflicted illness receive lower priority in access to healthcare resources? Mapping out the debate. Journal of Medical Ethics 2010;36(11):661-5.

14. Stegeman I, Willems DL, Dekker E, Bossuyt PM. Individual responsibility, solidarity and differentiation in healthcare. Journal of Medical Ethics 2014;40(11):770-3; Andersen MM, Nielsen MEJ. Luck egalitarianism, universal health care, and non-responsibility-based reasons for responsibilization. Res Publica 2015;21:1-16.

15. Thornton V. Who gets the liver transplant? The use of responsibility as the tie breaker. Journal of Medical Ethics 2009;35(12):739-42; Leong J, Im GY. Evaluation and selection of the patient with alcoholic liver disease for liver transplant. Clinics in Liver Disease 2012;16:851-63; Donckier V, Lucidi V, Gustot T, Moreno C. Ethical considerations regarding early liver transplantation in patients with severe alcoholic hepatitis not responding to medical therapy. Journal of Hepatology 2014;60:866-71.

16. Johri M, Ubel PA. Setting organ allocation priorities: Should we care what the public cares about? Liver Transplantation 2003;9:878-80; Waller BN. Responsibility and health. Cambridge Quarterly of Healthcare Ethics 2005;14:177-88. See also note 15, Thornton 2009.

17. Ho D. When good organs go to bad people. Bioethics 2008;22(2):77-83.

18. See note 16, Waller 2005. 